\title{
Prevention of different hydration options on cisplatin induced nephrotoxicity: a systematic review and meta analysis
}

\author{
$\mathrm{Yu} \mathrm{Wu}^{1}$, Yue Zhu ${ }^{1}$, Wanfen Zhang ${ }^{1}$, Cheng $\mathrm{Chen}^{1}$, and Tongqiang Liu ${ }^{1}$ \\ ${ }^{1}$ Affiliation not available
}

August 17, 2020

\begin{abstract}
Purpose:Cisplatin-induced nephrotoxicity (CIN) is still the most serious side effect limiting the use of cisplatin. It affects up to $20 \%$ of patients. So, there are many precautions to avoid it. The purpose of this study was to conduct a systematic review and meta-analysis to evaluate and determine different hydration options that could provide protection against cisplatininduced nephrotoxicity. Methods:A computerized literature search of PubMed, Embase, and Cochrane databases was performed. Trials were eligible if they enrolled patients receiving cisplatin and participants to receive different hydration options to prevent nephrotoxicity. We calculated odds ratios (ORs) and 95\% confidence intervals (CIs) for combinations of studies. Results:Within 1111 eligible studies, 31 articles fulfilling the selection criteria were included in the review. A meta-analysis could only be performed on the 9 retrospective studies concerning magnesium supplementation, and showed nephroprotective effect of CIN (OR0.21, [0.59-0.29]). Conclusion:Although up to now, there is no one method of prevention that shows its indisputable efficacy, our results highlight the potential protective effect of magnesium supplementation on CIN.
\end{abstract}

\section{Hosted file}

a system review and meta ananlysis.doc available at https://authorea.com/users/351458/ articles/476072-prevention-of-different-hydration-options-on-cisplatin-induced-

nephrotoxicity-a-systematic-review-and-meta-analysis 


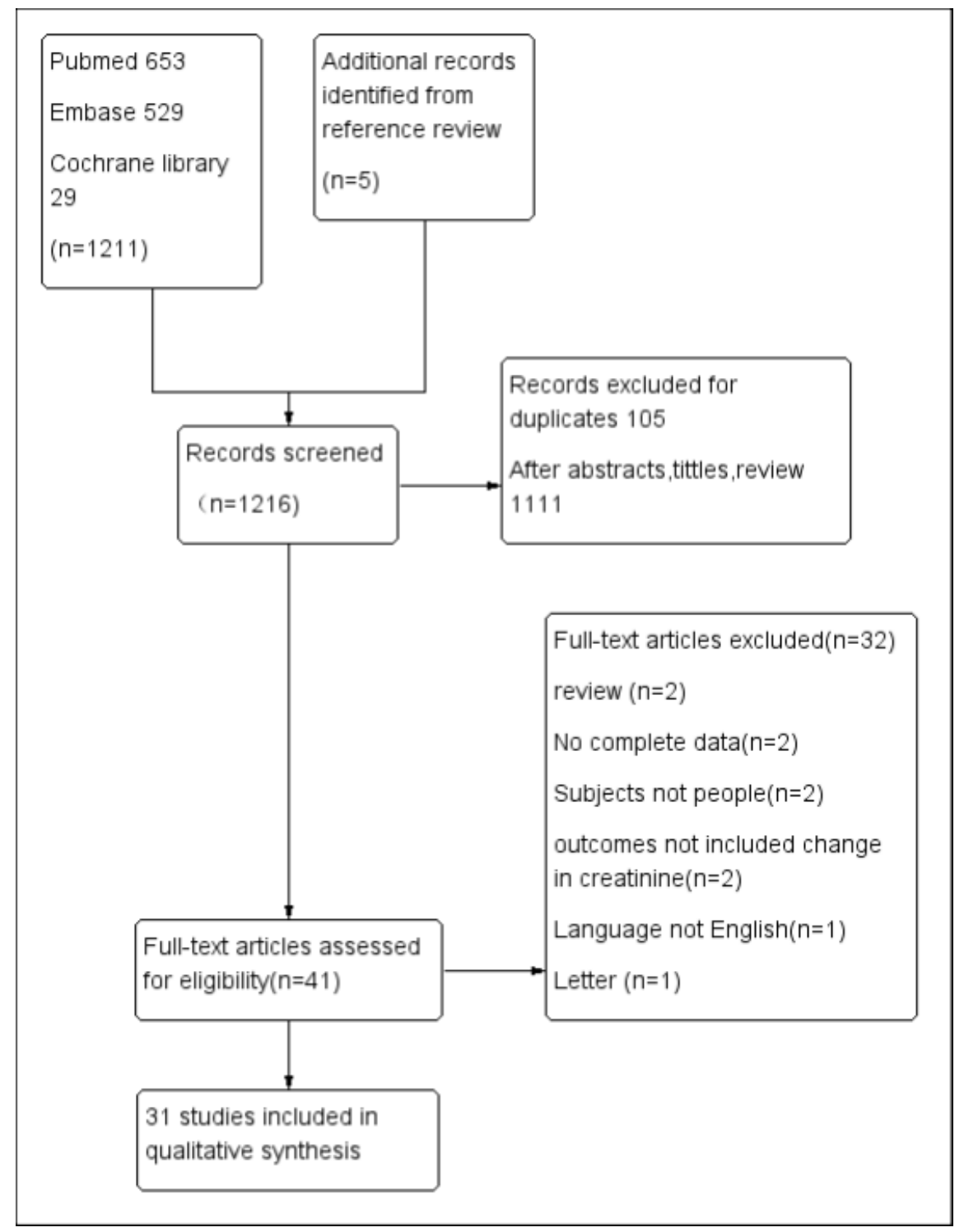



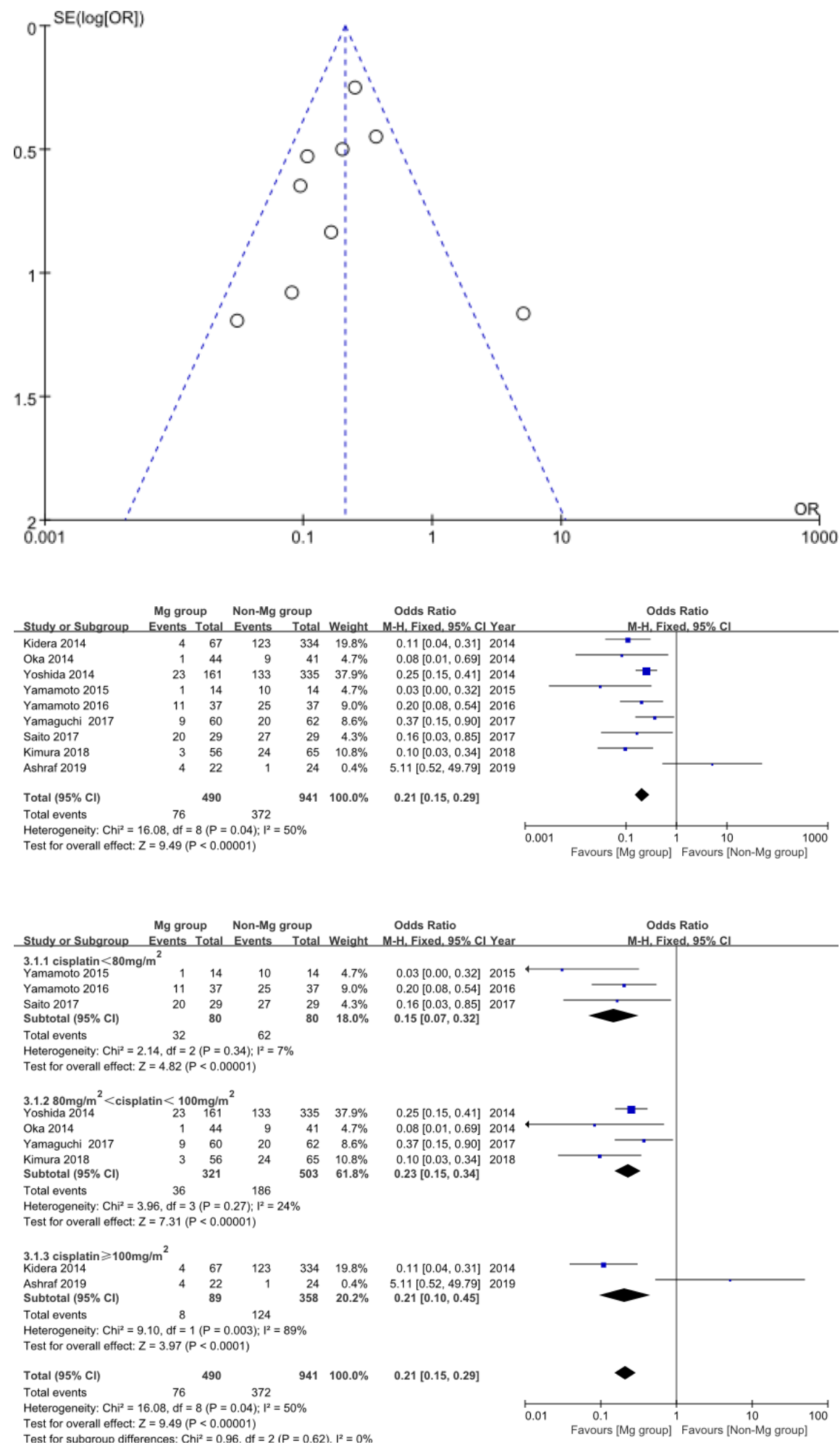

\section{Hosted file}

Table .docx available at https://authorea.com/users/351458/articles/476072-prevention-of- 
different-hydration-options-on-cisplatin-induced-nephrotoxicity-a-systematic-review-andmeta-analysis 